\title{
A Cost-Benefit Based, Parametric Procedure to Screen Existing Irrigation and Municipal Supply Reservoirs for Wind Energy Storage
}

\author{
Claudio Arena ${ }^{1, *}$, Mario Genco ${ }^{2}$, Alessio Lombardo ${ }^{2}$, Ignazio Meli ${ }^{3}$ and \\ Mario Rosario Mazzola ${ }^{1}$ \\ 1 Dipartimento di Ingegneria Civile, Ambientale, Aerospaziale e dei Materiali, Palermo University, \\ 90128 Palermo, Italy; mariorosario.mazzola@unipa.it \\ 2 Independent Researcher, 90142 Palermo, Italy; qanat.info@gmail.com (M.G.); \\ lombardo.alessio@hotmail.it (A.L.) \\ 3 Independent Researcher, 90143 Palermo, Italy; ingegneremeli@virgilio.it \\ * Correspondence: claudio.arena@unipa.it; Tel.: +39-339-189-2415
}

Received: 9 November 2018; Accepted: 3 December 2018; Published: 9 December 2018

\begin{abstract}
Pumped hydro storage (PHS) is one of the more suitable energy storage technologies to provide bulk storage of intermittent renewable energy sources (RES) such as wind. Since the main limiting factors to the expansion of this mature technology are environmental and financial concerns, the use of an existing reservoir can help mitigate both types of impacts. In addition, the high number of reservoirs for municipal and irrigation supply in many areas of the world makes the idea of using PHS as a relatively diffuse, open-market, technology for RES management attractive. These arguments in favor of PHS must, however, be convincing for investors and regulators from an economic standpoint. To this end, this paper presents a methodological tool to screen the feasibility of a PHS facility around an existing reservoir based on the principles of cost-benefit analysis, calibrated with data from Sicily, Italy. Each potential plant is characterized by two locational and two plant-specific parameters. Costs and benefits are assessed through a simulation model of the storage-release process on an hourly basis. Costs include both investment, and operation and maintenance expenditures, while the benefits considered include the opportunity cost of the current energy mix substituted by the stored energy, and the avoided $\mathrm{CO}_{2}$ emissions. The evaluation exercise is carried out parametrically, i.e., looking at a large number of combinations of the four parameters, in order to explore a wide range of possible plant configurations and to identify optimal ones under different locational conditions. A sensitivity analysis performed on models' parameters points out the sensitivity of results to benefit, rather than cost-related, input parameters, such as the efficiency of the generating and pumping system and the opportunity cost of energy.
\end{abstract}

Keywords: reservoirs; wind energy; pumped hydro storage; cost-benefit analysis

\section{Introduction}

The interest worldwide in energy storage issues has grown dramatically in the last years from governmental and planning agencies [1-6] and industry alike [7], due to the difficulty of integrating intermittent and hardly predictable renewable energy sources (v-RES), such as wind, in the existing grids. Among the different energy storage technologies, pumped hydro storage (PHS) is the most mature and widespread, used to store energy surpluses for many hours and release it to the grid when demanded.

When used for the purpose of storing energy surpluses deriving from intermittent RES, however, PHS systems operate in conditions that are different from those encountered in a conventional day-night, 
peak/off-peak, working mode [8-12]. Considering construction of a new plant therefore requires a thorough assessment of their techno-economic feasibility based on the specific supply-demand conditions at the appropriate timescale (typically one hour or less).

The major drawback of PHS as storage technology lies in the long construction times and environmental concerns [13]. Although there is a growing interest in smart, sustainable solutions, envisaging small PHS plants [14] especially for small islands and isolated grids [15-18], PHS plant construction is a major technical and financial effort. The full development of a PHS project takes approximately 15 years from time of inception to commissioning. Retrofitting of existing hydropower schemes with PHS has a lower environmental impact and is often seen as a more benign solution, as the receiving environment has already been modified and is regulated by the existence of the hydropower plant. Where hydropower reservoirs do not exist or are not adequately developed, an intermediate solution can be to use the storage capacities of existing water reservoirs for water supply. In fact, many reservoirs, especially those for irrigation, are often oversized and commonly feature active capacities well beyond the requirements of energy storage. From an energy market perspective, reduction of investment costs and the widespread presence of existing reservoirs may make this type of investment attractive to entrepreneurs, and hence generate a market of stored energy, to be suitably regulated, provided that it is able to produce positive net benefits for the society as a whole. Most European countries however, including Italy, are devoid of a specific regulation on pumped hydro storage [19].

Steps forward are underway to develop tools that analyze regional topography to identify potential sites for new PHS plants, even with an existing reservoir [20,21]. In the European Union, the most recent efforts in the analysis of pumped hydro storage potential at a national level throughout the continent are presented in Reference [22]. Reference [22], however, investigated pumped hydro potential almost exclusively in terms of its topographical suitability, undoubtedly a fundamental prerequisite for the development of PHS, without addressing financial and economical sustainability. This indicates that there is a knowledge gap in screening engineering-economic feasibility of this type of plants: PHS costs vary broadly and, even at a screening level, costs and benefits must be detailed enough to be convincing for investors and regulators. They need to reflect the actual main physical constraints in the processes that allow RES to be stored, and to be made available again to the grid.

In addition, the screening procedures developed so far do not specifically address the role of PHS as storage of power surpluses generated by wind farms. This study is hence motivated by the need to support planners, regulators, and investors with a simple, quick tool to appraise the economic feasibility of PHS as bulk energy storage for wind power surpluses, providing optimal plant configuration for a wide range of the main locational and technological parameters that characterize a PHS plant with an existing reservoir.

Conceptually, this study stands in between works that analyze the design of a specific PHS plant $[23,24]$, and others investigating the potential for the combined penetration of storage and RES expansion $[25,26]$. Other studies have also set the problem of energy storage in a cost-benefit framework [6]; the approach was however technology-neutral. In addition, the parametrical approach adopted in this study is, to the authors' knowledge, entirely novel.

In this work, the economical assessments were performed based on a cost-benefit analysis of the plant, producing indicators such as net present value (NPV), the internal rate of return (IRR) and the benefit-cost ratio $(B / C)$, which can be compared with other forms of storage for which similar indicators are available [27]. Furthermore, other indicators such as the levelized cost of energy (LCOE), as well as energy-related indicators, are evaluated. In developing the evaluation exercise, we did not concentrate on a specific demonstration site; rather, we carried out the assessments for a set of different locational and technical parameters, so as to provide a wide spectrum of different plants to be screened from the standpoint of their economic worth. Production and load data, however, do refer to a specific site, i.e., to Sicily as a whole: with its $25,000 \mathrm{~km}^{2}$ and a population of over $5,000,000$, Sicily is the largest and most populated island in the Mediterranean, and is energetically independent from 
the mainland. While conventional thermo-electric plants account for more than $90 \%$ of the energy produced in the island, RES, especially wind power, have been booming in Sicily in the last ten years, although bottlenecks in the grid and its overall obsolescence hinder a better exploitation of these type of resources. Sicily features 58 reservoirs, with a potential capacity of $2360 \mathrm{Mm}^{3}$. In Italy there are 538 dams recorded at the Italian Register of Dams, and 187 of them are in the South.

\section{Materials and Methods}

In this work, the whole island was treated as a single load center supplied by conventional sources and wind farms. The grid, with its operation rules and structural bottlenecks, was not considered in this study, so storable energy surpluses stem from comparing observed load with wind power production. Hourly load data are available for the last years, as well as wind power absorbed by the grid, also on an hourly basis. In this work, the 26,304 hourly data from years 2011-2013 were used.

\subsection{Estimation of Wind Power Production Data}

In 2011-2013 Sicily had on average 54 working wind farms (Figure 1), with an increase from 53 at the beginning to 56 at the end of the period. As production data were not available, they were reconstructed for each wind farm using average hourly wind speed data at $2 \mathrm{~m}$ or $10 \mathrm{~m}$, when available, from SIAS, the Sicilian Agro-meteorological Service [28]. SIAS provides on-line measurements mainly for the purpose of crop management, implying that location of meteorological stations was not selected in light of wind energy development. This may constitute a potential source of bias in the estimation of energy production. As the location of wind farms does not coincide with that of the gauge stations, wind data were selected by a criterion of proximity and similarity: a number of wind farms were associated to a single gauge station, as shown in Figure 1.

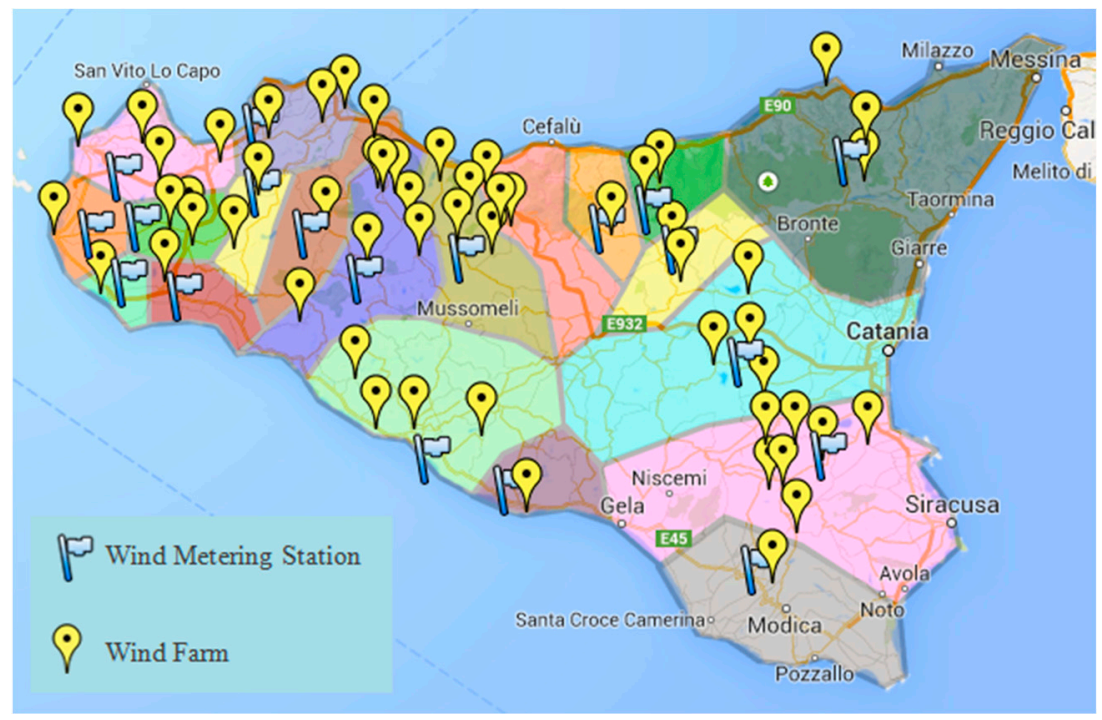

Figure 1. Location of wind farms in Sicily and wind metering stations used to reconstruct wind power production. The colored areas cover clusters of wind farms of which production is assessed using data from the same wind gauge station.

Wind speeds at $2 \mathrm{~m}$ or $10 \mathrm{~m}$ were first turned to the wind speed at the hub height of the turbines of the specific plant, through the Hellmann power law with an exponent of 0.25 . Power production was assessed from wind speed using the wind speed-power characteristic of each specific wind farm, accounting for the turbine-specific cut-in and cut-off thresholds, i.e., wind speeds below and over which no energy is produced. Eighteen different types of turbines were detected in the surveyed plants. In addition, a row factor of 0.90 and an availability factor of 0.95 were multiplied by the production of each plant's turbines to account for both interference among turbines and out-of-service periods. 
The resulting aggregated wind power production (i.e., the sum in each hour of production from all the plants) looks quite realistic, both in terms of number of equivalent hours (averagely 1681 in 2011-2013) and in terms of overall average yearly energy production $(2800 \mathrm{GWh})$, which is quite close to the wind power absorbed by the grid.

\subsection{Load Data}

Spells of wind energy surplus are obtained by comparing production with load for each hour of years 2011-2013. Here load is the wind energy absorbed by the grid, as provided by Terna, the grid operator (www.terna.it). Clearly, the amount of wind energy absorbed by the grid in a certain hour depends not only by the overall energy demand in that hour, but also on the specific condition of the grid and on the way the grid is managed. A more complete approach would hence require that the whole energy dispatch process be simulated, considering the overall energy demand, introducing some reasonable dispatch rule and assessing how energy demand is allocated among the different supply sources. Given the exploratory character of this work, this was not done, but, as said, the duration and magnitude of surpluses was obtained by comparing the estimated potential wind power production with wind power absorption in each hour of years 2011-2013.

\subsection{The Evaluation Model}

In a scheme with an existing reservoir and the other one to be built, the evaluation model simulates the refill-drawdown process of the upper reservoir during the spells of power surplus/demand. Surplus events are constituted by consecutive hours in which wind power production WP exceeds demand DEM, giving rise to a power surplus $w$ (in MW). The $j$-th event is characterized by a duration $\mathrm{Tj}$, and by a magnitude $\mathrm{Mj}$ defined as:

$$
M_{j}=\sum_{i=t 1_{j}}^{t 1_{j}+T_{j}+1} w(i)=\sum_{i=t 1_{j}}^{t 1_{j}+T_{j}+1} W P(i)-\operatorname{DEM}(i)
$$

where $t 1_{j}$ is the initial hour of the $j$-th surplus event. Figure 2 depicts the characteristics of the surplus events in terms of duration and magnitude for years 2011-2013 separately. The elbow shape of these relationships is the consequence of the highly skewed distribution of hourly wind speeds, and gives rise to a considerable scope for optimization when defining the design variables (first of all, storage capacity and installed power) of the PHS plants. These aspects are however better analyzed through a simple model of the storage-release process, illustrated in the following section.

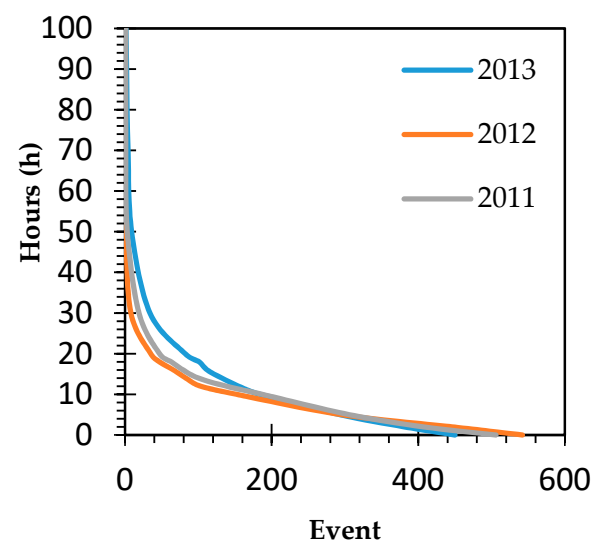

(a)

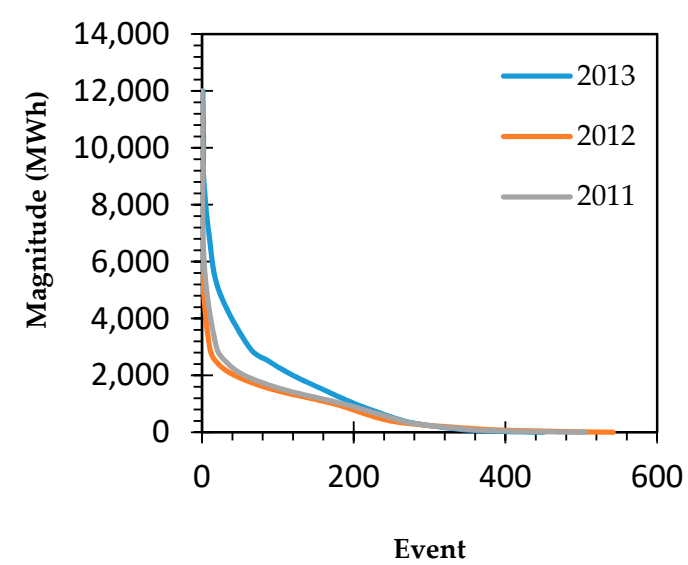

(b)

Figure 2. (a) Distribution of the duration of events of wind power surplus for years 2011-2013; (b) magnitude of wind power surpluses for the same period. 


\subsubsection{Modelling the Storage-Release Process}

The governing equations of the simulation model are the following:

$$
\begin{gathered}
\mathrm{S}_{\mathrm{t}+1}=\min \left[\mathrm{K}, \mathrm{S}_{\mathrm{t}}+\mathrm{Q}_{\mathrm{t}}-\mathrm{R}_{\mathrm{t}}\right] \\
\mathrm{Q}_{\mathrm{t}} \times \mathrm{R}_{\mathrm{t}}=0 \\
\mathrm{Q}_{\mathrm{t}}=\min \left\{\eta_{\mathrm{p}} \times \mathrm{w}_{\mathrm{t}} /[3.6 \times \mathrm{g} \times(\mathrm{H}+\Delta \mathrm{Y})], \mathrm{Q}_{\max }^{*}\right\} \\
\Delta \mathrm{Y}=\beta \times\left(\mathrm{Q}_{\mathrm{t}} / 3600\right)^{2} / \mathrm{D}^{5} \times \mathrm{L} \\
\beta=0.00162+0.000042 / \mathrm{D} \\
\mathrm{R}_{\mathrm{t}}=\min \left\{\mathrm{S}_{\mathrm{t}}, \mathrm{R}_{\max }\right\} \\
\mathrm{R}_{\max }=\mathrm{Q}_{\text {max }}^{*}=3600 \times \mathrm{n} \times \omega_{\text {pipe }} \times \mathrm{v}_{\max }
\end{gathered}
$$

In Equation (2), St is the water volume stored in the upper reservoir in the $\mathrm{t}$-th hour of simulation, $Q_{t}$ is the pumped water from the lower reservoir in the $t$-th hour $\left(Q_{t}>0\right.$ only during a surplus event), $K$ is upper reservoir's active capacity, and $R_{t}$ is the release from the upper reservoir. $R_{t}>0$ only outside surplus events, so that $R_{t} \times Q_{t}=0$. All quantities are in $\mathrm{m}^{3}$.

In Equation (3), $\mathrm{H}$ (in $\mathrm{m}$ ) is the net head between water levels in the upper and lower reservoirs. $\mathrm{H}$ was assumed constant along the year, which is not always the case, especially for existing reservoirs with seasonal uses such as irrigation. The efficiency of the pumping system, $\eta_{p}$, is set equal to 0.85 ; $\mathrm{g}\left(\right.$ in $\mathrm{ms}^{-2}$ ) is the acceleration of gravity, $\mathrm{w}_{\mathrm{t}}$ is the available energy surplus (in MW), $\Delta \mathrm{Y}$ (in $\mathrm{m}$ ) is friction loss along the pipes, and $\mathrm{Q}_{\max }^{*}$ is the maximum volume conveyable in a hour by $\mathrm{n}$ independent pipes, each of diameter D (in m). In Equation (4), L (in $\mathrm{m}$ ) is the length of the pipes connecting bidirectionally the upper and the lower reservoir, $\mathrm{D}$ is the pipes' diameter (assumed constant for all pipes), and $\beta$ is Darcy's friction factor for steel pipes (Equation (4a)).

Upon substitution of (4a) in (4) and (4) in (3), the following cubic equation results:

$$
\mathrm{Q}_{\mathrm{t}}^{3}+\mathrm{H} \times \mathrm{D}^{5} /(\beta \mathrm{L}) \mathrm{Q}_{\mathrm{t}}-\left(\eta_{\mathrm{p}} \times \mathrm{w}_{\mathrm{t}} \times \mathrm{D}^{5}\right) /(1000 \times \mathrm{g} \times \beta \times \mathrm{n} \times \mathrm{L})
$$

which can be handled in closed form through the Cardan solution [29].

In simulating the release process, it is assumed that release $R_{t}=R_{\max }$, unless water in the reservoir is not sufficient, in which case $R_{t}=S_{t}$. According to Equation (6), $R_{\max }$ is given by the flow that can be conveyed at the maximum admissible velocity $\mathrm{v}_{\max }$ by the $\mathrm{n}$ pipes connecting bidirectionally the upper and lower reservoir, each having an internal section of $\omega\left(\right.$ in $^{2}{ }^{2}$ ). Although both $n, D$ (and hence $\omega)$, and $v_{\max }$ could be selected by an optimization study, we rather adopted the following reference values for $D$ and $v_{\max }: D=2 \mathrm{~m}, \mathrm{v}_{\max }=4 \mathrm{~m} / \mathrm{s}$. We then obtained $\mathrm{n}$, recalling that the maximum flow that can be pumped by a pump system with installed power $P$ is:

$$
\mathrm{Q}_{\max }=\mathrm{P} \times \eta_{\mathrm{p}} /(9.81 \times \mathrm{H})
$$

where $D_{\max }=4 Q_{\max } /\left(\pi \times v_{\max }\right)$, and subsequently

$$
\mathrm{n}=\left(\mathrm{D}_{\max } / \mathrm{D}\right)^{2}
$$

Equations (2)-(6) contain the four main parameters describing a PHS plant for wind energy storage with an existing reservoir. Two of these parameters are locational, namely $\mathrm{L}$ and $\mathrm{H}$, and characterize the site where the plant is located; as such they must be considered design parameters. The other two are $\mathrm{K}$ and $\mathrm{P}$ : they are plant-specific and can be considered as design variables.

Given a discrete domain for each of these four parameters (Table 1), we consider all their combinations in order to simulate the performances of a broad spectrum of different plants. For each 
$(\mathrm{H}, \mathrm{L}, \mathrm{K}, \mathrm{P})$ combination, the time series of power surpluses $\mathrm{w}_{\mathrm{t}}$ (including $\mathrm{w}_{\mathrm{t}}=0$ when production is less than demand) for the 26,304 h of triennium 2011-2013 can be routed through Equations (2)-(6), and for each time step energy production may be evaluated:

$$
\text { Erel }_{\mathrm{t}}=3.6 \times \eta_{\text {turb }} \times 9.81 \times \mathrm{R}_{\mathrm{t}} \times(\mathrm{H}-\Delta \mathrm{Y})
$$

where $\eta_{\text {turb }}$ is the efficiency of the power generation system (the turbines), set equal to 0.90 . From Equation (10), the overall energy produced during the three year period can be assessed as

$$
\text { Erel }_{\text {tot }}=\sum_{\mathrm{t}=1}^{\mathrm{N}_{\text {hours }}} \text { Erel }_{\mathrm{t}}
$$

The energy absorbed by the plant at time $t$ (in MWh) can be defined as:

$$
\mathrm{Eabs}_{\mathrm{t}}=3.6 \times \mathrm{Q}_{\mathrm{t}} \times 9.81 \times(\mathrm{H}+\Delta \mathrm{Y}) / \eta_{\mathrm{p}}
$$

and the energy absorbed over the whole simulation period is given by

$$
\text { Eabs }_{\text {tot }}=\sum_{\mathrm{t}=1}^{\mathrm{N}_{\text {hours }}} \text { Eabs }_{\mathrm{t}}
$$

Table 1. Values of the four locational $(\mathrm{H}$ and $\mathrm{L})$ and design $(\mathrm{P}$ and $\mathrm{K})$ parameters used in the parametric analysis.

\begin{tabular}{cccc}
\hline $\mathbf{H}(\mathbf{m})$ & $\mathbf{L}(\mathbf{k m})$ & $\mathbf{P}(\mathbf{M W})$ & $\mathbf{K} \mathbf{( M m}^{\mathbf{3}} \mathbf{)}$ \\
\hline 50 & 1 & 5 & 0.02 \\
100 & 3 & 10 & 0.05 \\
150 & 5 & 20 & 0.10 \\
200 & 10 & 50 & 0.50 \\
300 & & 100 & 1.00 \\
400 & & 150 & 1.50 \\
& & & 2.00 \\
& & & 2.50 \\
& & & 3.00 \\
& & & 3.50 \\
& & & 5.00 \\
\hline
\end{tabular}

2.3.2. Assessing the Economic Indicators of the Plant

For each $(\mathrm{H}, \mathrm{L}, \mathrm{K}, \mathrm{P})$ combination, the following indicators were assessed:

1) NPV of the plant:

$$
\mathrm{NPV}=-\mathrm{C}_{0}+\sum_{\mathrm{y}=1}^{\mathrm{N}}\left(\mathrm{B}_{\mathrm{y}}-\mathrm{C}_{\mathrm{y}}\right) /(1+\mathrm{r})^{\mathrm{y}}
$$

where $C_{0}$ is the investment cost, assumed concentrated in year $0, B_{y}$ is the benefit in year $y, C_{y}$ is the cost in year $y$ and $r$ is the social discount rate (SDR), set equal to 3.5\% [30]. The methodology to obtain costs is illustrated in 2.3.3, and benefit estimation is reported at 2.3.4. After $\mathrm{N}$ years, at the end of the planning period, a residual value of the existing infrastructure should be considered. In addition, depending on $\mathrm{N}$, the cost for equipment renewal should be concentrated in some year distant from the first one (say the 20th or the 30th). In this analysis, the planning horizon was set equal to 25 years so to avoid considering renewal costs, while residual value was conservatively omitted. 
It should be observed that from the standpoint of a public planner/regulator, which is the one adopted here, an economic, rather than a financial approach is appropriate to carry out a cost-benefit analysis of this kind of investment. From this perspective, another choice leading to conservative results was to avoid consideration of conversion factors that are used in practical CBA to account for distortions in certain markets of interest for the analysis [30,31]. In this specific case, markets such as labor and that of large, patented, pumping and power generation systems can hardly be considered undistorted: avoiding consideration of their conversion factors leads to a more conservative (severe) estimation of costs and hence to an understatement of the economic indicators.

2) IRR of the plant: the discount rate that makes NPV $=0$.

3) B/C: the ratio between actualized benefits and costs:

$$
\mathrm{B} / \mathrm{C}=\sum_{\mathrm{y}=1}^{\mathrm{N}}\left[\mathrm{B}_{\mathrm{y}} \times(1+\mathrm{r})^{\mathrm{y}}\right] /\left\{\mathrm{Co}+\sum_{\mathrm{y}=1}^{\mathrm{N}}\left[\mathrm{C}_{\mathrm{y}} \times(1+\mathrm{r})^{\mathrm{y}}\right]\right\}
$$

4) LCOE, the levelized cost of energy:

$$
\mathrm{LCOE}=\sum_{\mathrm{y}=1}^{\mathrm{N}}\left[\left(\mathrm{IC}_{\mathrm{y}}+\mathrm{M}_{\mathrm{y}}+\mathrm{F}_{\mathrm{y}}\right) /(1+\mathrm{r})^{\mathrm{y}}\right] / \sum_{\mathrm{y}=1}^{\mathrm{N}}\left[\operatorname{Erel}_{\mathrm{y}} /(1+\mathrm{r})^{\mathrm{y}}\right]
$$

where $\mathrm{IC}_{\mathrm{y}}, \mathrm{M}_{\mathrm{y}}$ and $\mathrm{F}_{\mathrm{y}}$ respectively represent investment, operation and maintenance costs $(\mathrm{O} \& \mathrm{M})$, and fuel expenditures in year $\mathrm{y}$. LCOE has the dimension of a price and is similar to B/C ratio, except that benefits are not quantified explicitly.

In addition to these economical parameters, the energy efficiency of the plant can be defined as the ratio between the energy produced and the energy absorbed by the plant:

5) $\quad$ Eff $=$ Erel $_{\text {tot }} /$ Eabs $_{\text {tot }}$

Finally, a saturation index may be defined, as the ratio between energy produced and the total energy surplus:

6) Sat $=$ Erel $_{\text {tot }} / W_{\text {tot }}$

The first three indicators require an explicit assessment of both costs and benefits of the plant.

\subsubsection{Cost Assessment}

The cost items considered in the evaluation are reported in Table 2. It shows that the some of them are expressed as a function of the three main cost items, namely reservoir, pipelines, and turbines.

Table 2. Cost items, parametric investment cost models, and maintenance costs considered in

\begin{tabular}{|c|c|c|c|}
\hline Symbol & Cost Item & Parametric Investment Cost Model & $\begin{array}{l}\text { Maintenance } \\
\text { Costs ( } € / \text { year) }\end{array}$ \\
\hline $\mathrm{C}_{\mathrm{K}}$ & Upper reservoir & $\mathrm{C}_{\mathrm{k}}=\mathrm{K} \times 0.0038 \times(\mathrm{K})^{-0.35} / 1.275 \mathrm{~K}\left(\mathrm{~m}^{3}\right)$ & $0.0025 \times \mathrm{C}_{\mathrm{K}}$ \\
\hline $\mathrm{C}_{\text {pipes }}$ & Pipelines & $\begin{array}{c}\mathrm{C}_{\text {pipes }}=0.0375 \times(\mathrm{D})^{1.4562} \times \mathrm{N}_{\mathrm{T}} \times \mathrm{L} \\
\mathrm{D}(\mathrm{mm}) \mathrm{L}(\mathrm{m})\end{array}$ & $0.0015 \times C_{\text {pipes }}$ \\
\hline $\mathrm{C}_{\text {turb }}$ & $\begin{array}{l}\text { Power Generation } \\
\text { (Turbines and equipment) }\end{array}$ & $\begin{aligned} \mathrm{C}_{\text {turb }}= & 1.1948 \times(\mathrm{P})^{0.7634} \times \mathrm{N}_{\text {turb }} \times \\
& 0.82234 \times 10^{6} \mathrm{P}(\mathrm{MW})\end{aligned}$ & $0.0030 \times \mathrm{C}_{\text {turb }}$ \\
\hline $\mathrm{C}_{\text {pump }}$ & Pumping System & $0.5 \times \mathrm{C}_{\text {turb }}$ & $0.0040 \times C_{\text {pump }}$ \\
\hline $\mathrm{C}_{\text {acc_res }}$ & $\begin{array}{l}\text { Reservoir ancillary works (fencing, } \\
\text { lighting, access roads etc.) }\end{array}$ & $0.15 \times C_{\text {res }}$ & $0.0030 \times C_{\text {acc_res }}$ \\
\hline $\mathrm{C}_{\text {acc_turb }}$ & $\begin{array}{l}\text { Pumping and generation ancillary } \\
\text { works (power and pump house, } \\
\text { keeper's house, services etc.) }\end{array}$ & $0.05 \times \mathrm{C}_{\text {turb }}$ & $0.0040 \times \mathrm{C}_{\text {acc-turb }}$ \\
\hline $\mathrm{C}_{\text {Land }}$ & Land & $0.005 \times\left(C_{\text {res }}+C_{\text {pipes }}+C_{\text {turb }}+C_{\text {pump }}\right)$ & \\
\hline $\mathrm{C}_{\mathrm{S}}$ & $\begin{array}{l}\text { Electric substation and connection } \\
\text { to AC grid }\end{array}$ & $0.20 \times\left(C_{\text {turb }}+C_{\text {pump }}\right)$ & \\
\hline $\mathrm{C}_{\mathrm{TE}}$ & Technical expenditures & $\begin{array}{c}0.1 \times\left(C_{\text {res }}+C_{\text {pipes }}+C_{\text {turb }}+C_{\text {pump }}+\right. \\
\left.C_{\text {acc_res }}+C_{\text {acc_turb }}+C_{\text {Land }}+C_{\text {s }}\right)\end{array}$ & \\
\hline
\end{tabular}
the analysis. 
For each active reservoir capacity of Table 1, a reservoir was designed. For simplicity's sake, a rectangular shape was selected (Figure 3). Each was assumed to have a fixed depth of $8 \mathrm{~m}$, regardless of capacity. Unit costs for excavation, building of the slopes, waterproofing etc. were drawn from the official price lists for public works, issued yearly by the regional administration [32]. A mix of different soil types was assumed to estimate excavation costs [19]. From the eight different tank designs, an interpolating curve was obtained that allows cost estimation also for reservoir sizes different from the eight considered. The pipelines connecting the upper reservoir to the existing one were assumed to be of weldless steel. As mentioned, a single diameter $(\mathrm{D}=2 \mathrm{~m})$ was adopted for all the pipes, with a unit cost (including installation costs) of $2424 € / \mathrm{m}$. Turbine costs were evaluated through data, from a database of turbine costs from 81 power stations in 32 countries worldwide [33].

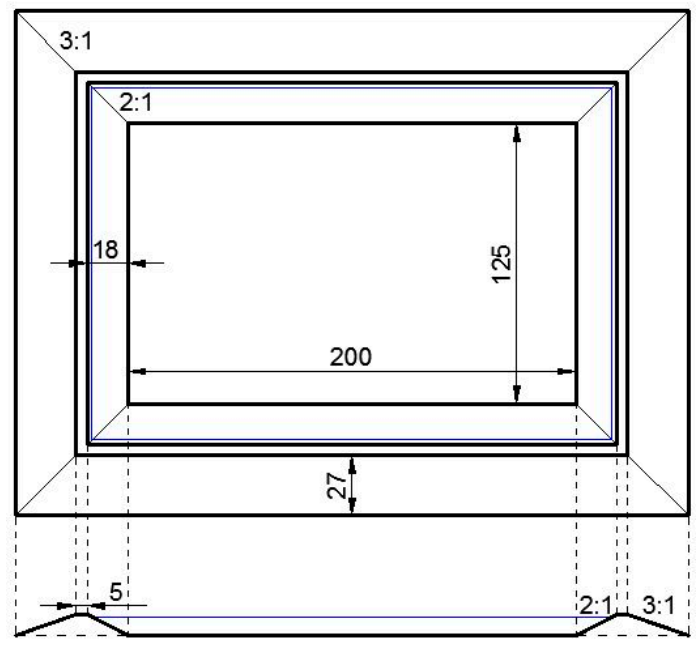

Figure 3. Design scheme for the new, upper reservoir. Dimensions are in $\mathrm{m}$ and refer to $\mathrm{K}=0.2 \mathrm{Mm}^{3}$.

Other costs were estimated as linear combinations of the three previous ones, as shown in Table 2. The same also applies for operation and maintenance costs (O\&M), which are also reported in Table 2. In addition to these costs, personnel and service costs as well as overheads were considered: personnel costs were evaluated by assuming that the staff required to operate the plant be composed by a plant manager, two units for plant conduction and three plant keepers, for a yearly cost of $0.43 \mathrm{M} €$ overall, based on current labor costs, including taxes and social security. Service costs include here a fixed part (bills, water, wastewater treatment etc.), set equal to $0.01 \mathrm{M} €$ /year, and a variable part, set equal to $1.0 \%$ of personnel and O\&M costs. Finally, overheads are set equal to $10 \%$ of the sum of personnel, O\&M and service costs.

As far as investment costs are concerned, the average breakdown by the expenditure types of Table 2 for fourteen optimal plant configurations, in the sense described further in Section 3, is the following: $\mathrm{C}_{\mathrm{K}}=23 \%$ (with a standard deviation $\mathrm{SD}$ of $\left.2.8 \%\right), \mathrm{C}_{\text {pipes }}=15 \%(\mathrm{SD}=7.8 \%$ ), $\mathrm{C}_{\text {turb }}+\mathrm{C}_{\text {pump }}=40 \%(\mathrm{SD}=5.2 \%), \mathrm{CTE}=9 \%(\mathrm{SD}=0.2 \%)$, and $13.2 \%$ for all the other cost items of Table $2(\mathrm{SD}=1.5 \%)$. Overall, the small value of $\mathrm{SD}$ for the various cost typologies indicates that the average cost breakdown is quite representative of a wide class of investments, with the cost of the new reservoir weighing on total investments for $23 \%$. The high standard deviation of $C_{\text {acc_res }}$ is due to the fact that the optimal plants selected to assess this average cost breakdown refer to different values of parameter $\mathrm{L}$, ranging from $1000 \mathrm{~m}$ to $10,000 \mathrm{~m}$.

\subsubsection{Benefits Assessment}

The benefits produced by a PHS plant as energy storage are manifold [34-37]. They include, besides energy storage bulk capacity, transmission grid ancillary benefits, such as firming capacity and 
reserves, reactive power, black start capability, spinning reserve, and overall balancing and voltage and/or frequency stability of the grid, for time spans ranging from seconds to hours.

In this work we only concentrated on the benefits associated to the bulk storage function, the one that allows energy storage for many hours. This approach is conservative, in that benefits generated by the plant are certainly higher than those obtained here. Two types of benefits were considered: the first type is generated by the fact that stored energy, when released, substitutes energy produced by the current sources; energy surpluses are assumed to be withdrawn from the grid for free and released when needed. This assumption holds certainly true if the PHS plant is built by a wind power producer or by the grid operator. Strictly speaking, this type of benefit should be expressed as the opportunity cost of the saved energy, to be assessed as the long run marginal cost (LRMC) of the energy mix. In this exercise, the average unit price of energy in the target area (Sicily) was taken as a proxy of the economic value of the current energy mix.

This price assumption seems conservative, as this type of stored energy could be used to cover peak demands and hence substitutes for the costliest sources such as turbo-gas generators; the effect of storage on price was analyzed, with different outcomes [38-40]; in this analysis we stuck to average values. The second type of benefit is associated with the reduction of $\mathrm{CO}_{2}$ emissions. To assess this external effect, released energy was first turned into avoided tons of $\mathrm{CO}_{2}$ using an emission coefficient of $433.2 \mathrm{CO}_{2}$ tons/GWh, according to Italian technical standard UNI/TS 11300-4; the economic value of avoided $\mathrm{CO}_{2}$ tons was then attributed using the reference tables of the European Commission [29], which provide for each year of application (from 2010 to 2050) a range of values (lower-central-upper, in $€ / \mathrm{CO}_{2}$ tons) for the avoided emissions. For this application, the central value, spanning from $25 € / \mathrm{CO}_{2}$ ton in 2010 to $85 € / \mathrm{CO}_{2}$ ton in 2050 , was used.

\section{Results and Discussion}

As a first result, Figure 4 shows the percentage of economically worthwhile PHS plants classified by H, (Figure 4a), L (Figure 4b), P (Figure 4c) and K (Figure 4d). A plant, identified by a combination of these four parameters, is economically sustainable if it displays favorable economic indicators (NPV $>0$, IRR $>3.5 \%, \mathrm{~B} / \mathrm{C}>1$ ); overall, around $24 \%$ of the 1728 screened plants showed a NPV $>0$ and an IRR $>3.5 \%$. The plots of Figure 4 help identifying a lower bound for the head, which is located around $70-80 \mathrm{~m}$, below which setting up a PHS plant is not economically sustainable (no plant is economically feasible for $\mathrm{H}=50 \mathrm{~m}$ ).

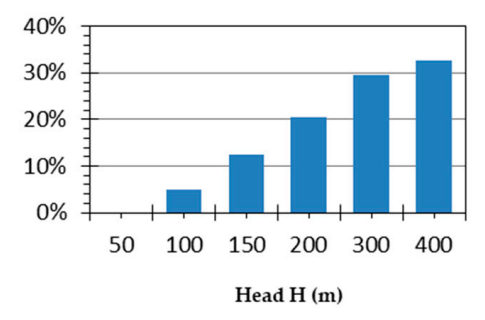

(a)

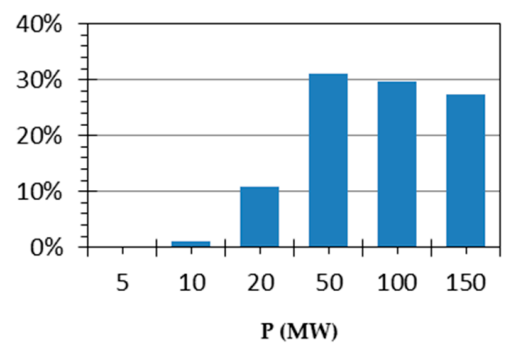

(c)

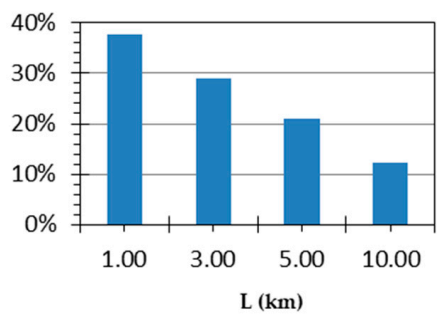

(b)

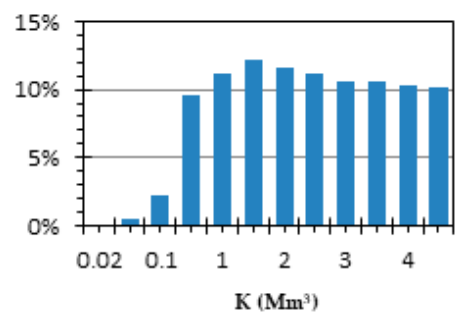

(d)

Figure 4. Percentage of economically worthwhile plants classified by head (a), distance between reservoirs (b), installed power (c), and active storage capacity $(\mathbf{d})$. 
Results are less clear-cut when it comes to identifying a feasibility threshold for the distance between the reservoirs: $10 \%$ of the economically feasible plans still fell within the $10 \mathrm{~km}$ distance, most likely with a high head. This suggests that, in some instances, it may be worthwhile looking for suitable locations for the new reservoir even when the distance from the existing one is significant. According to Figure 4c, plants with installed power less than $10 \mathrm{MW}$ are not likely to be economically feasible, while the highest density of economically feasible plants is found for $\mathrm{P} \geq 50 \mathrm{MW}$. Figure $4 \mathrm{~d}$ shows that the distribution of active storage capacity was rather uniform for $\mathrm{K} \geq 0.5 \mathrm{Mm}^{3}$, but smaller capacities can be also appropriate, albeit for a limited, selected number of other locational and installed power scenarios. The interplay among the four parameters can be investigated by plotting one of the selected economic indicators against one parameter, e.g., capacity, for different values of the other design parameter, e.g., installed power, for each combination of the locational parameters $\mathrm{H}$ and $\mathrm{L}$. As an example, Figure $5 \mathrm{a}-\mathrm{h}$ shows these plots for $\mathrm{H}=200 \mathrm{~m}$ and $\mathrm{L}=3000 \mathrm{~m}$, but the comments apply comprehensively to all the different combinations plotted.

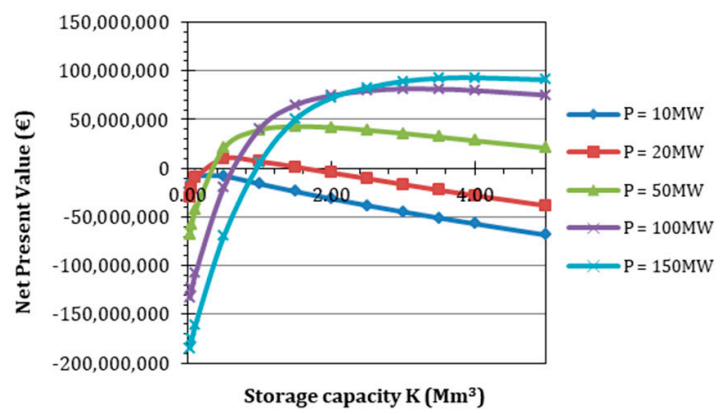

(a)

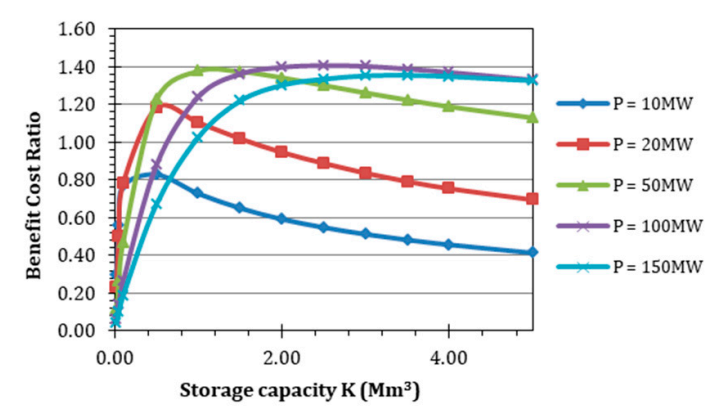

(c)

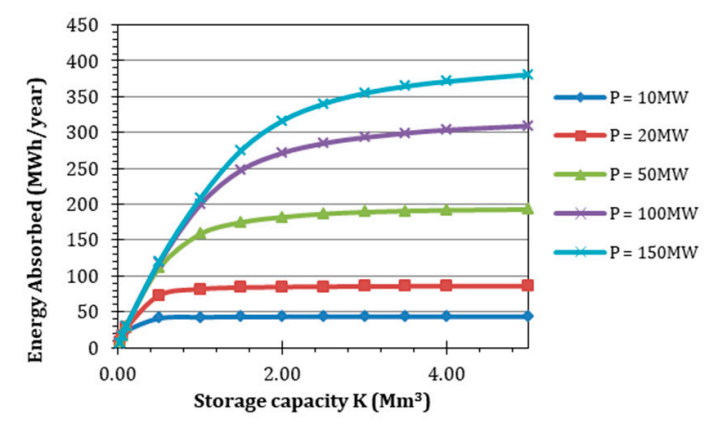

(e)

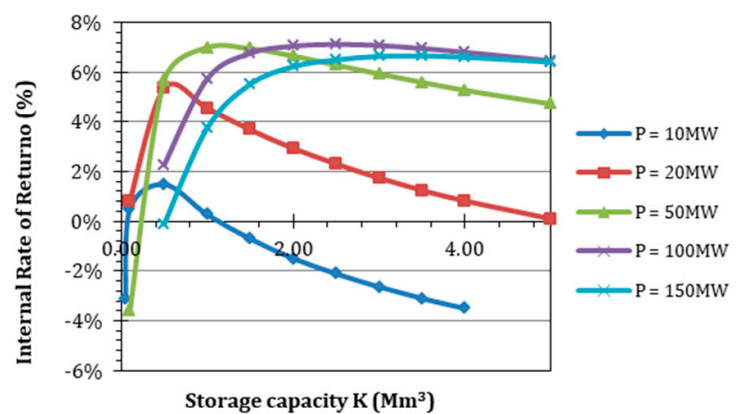

(b)

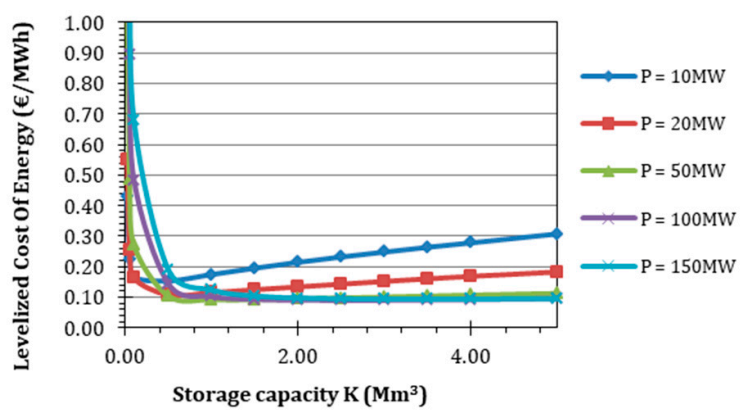

(d)

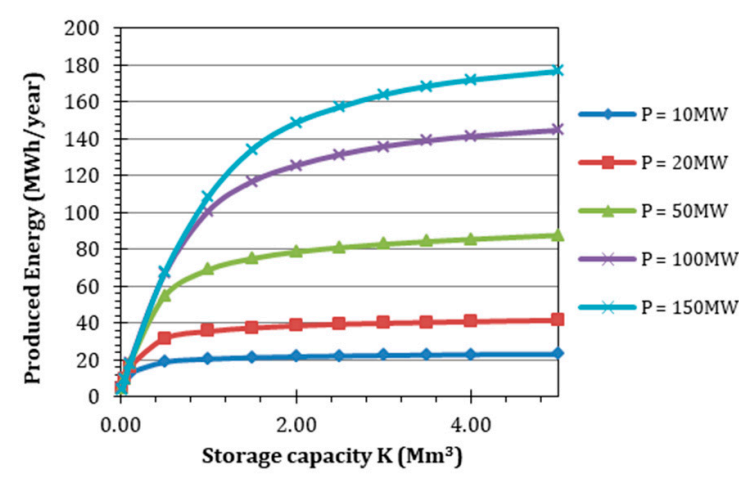

(f)

Figure 5. Cont. 


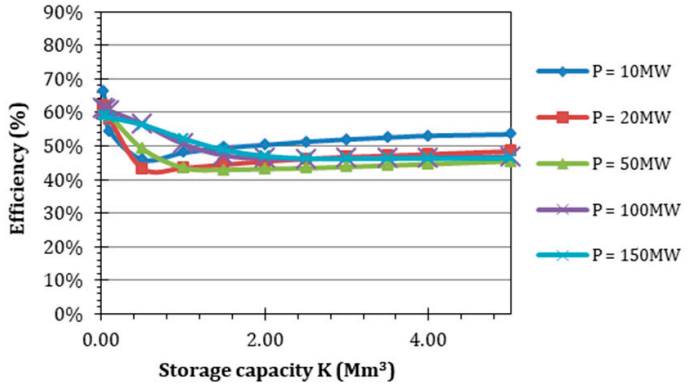

(g)

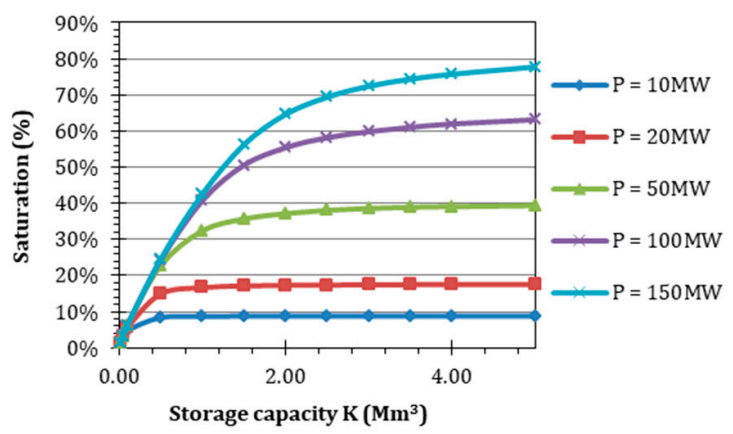

(h)

Figure 5. (a) NPV, (b) IRR, (c) B/C, (d) LCOE, (e) Eabs tot, (f) Erel tot, (g) efficiency and (h) saturation as a function of storage capacity for different power capacities. $\mathrm{H}=200 \mathrm{~m}$ and $\mathrm{L}=3000 \mathrm{~m}$.

It should also be observed that both efficiency and saturation take on values that are in most cases less than $70 \%$, i.e., lower than the $75-80 \%$ reported in the literature [41]. On the one hand, this confirms the conservativeness of the assumptions upon which these results are based, and on the other hand it is encouraging from the standpoint of efficiency enhancements when detailed design is performed on a specific site [23]; efficiency can also be increased using variable speed pumping systems [42,43]. Energy indicators Erel tot $_{\text {and }}$ Eabs $_{\text {tot }}$ exhibited decreasing marginal values with K, i.e., they grew steadily for low $\mathrm{K}$ values, but they tended towards an asymptotic value, faster the smaller the power capacity, as should be expected. Saturation showed a similar pattern, while efficiency showed a minimum for $\mathrm{K}$ values where Eabs $\mathrm{tot}_{\text {tot }}$ has an elbow. For low values of the installed power, the economic indicators all exhibited a maximum storage capacity, while for larger installed powers this maximum was not directly detectable, as it probably fell outside the $\mathrm{K}$ domain adopted in this study. For large installed power, however, a decreasing marginal value for these indicators was recognizable, pointing out that increasing storage capacity leads to benefits that are bound to be outweighed by investment costs. For all $(\mathrm{H}, \mathrm{L})$ pairs, plots like those of Figure 5 were analyzed in order to find the pairs $(\mathrm{K}, \mathrm{P})$ that maximized a given economic indicator. This search process was performed on the IRR rather than on the NPV because, like the $\mathrm{B} / \mathrm{C}$ ratio, it is a dimensionless indicator and allows comparison with other storage technologies or different investment projects. As a result, functions $\mathrm{P}^{*}=\mathrm{f}\left(\mathrm{K}^{*}\right):\left(\mathrm{P}^{*}, \mathrm{~K}^{*}\right)=\arg _{\max }(\mathrm{IRR} \mid \mathrm{H}, \mathrm{L})$ were developed. Figure 6 shows such relationships for different $\mathrm{H}$ and $\mathrm{L}$ combinations, from the less advantageous ( $\mathrm{H}$ small, $\mathrm{L}$ large), to the most favorable ones.

(a)

$\mathrm{L}=1000 \mathrm{~m}, \mathrm{H}=100 \mathrm{~m}$

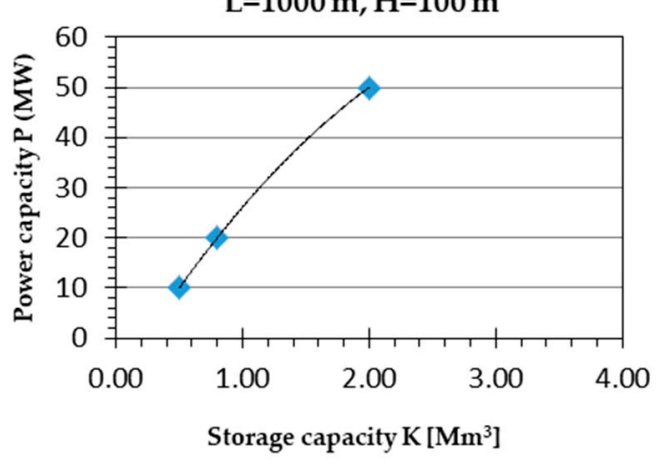

(b)

$\mathrm{L}=1000 \mathrm{~m}, \mathrm{H}=400 \mathrm{~m}$

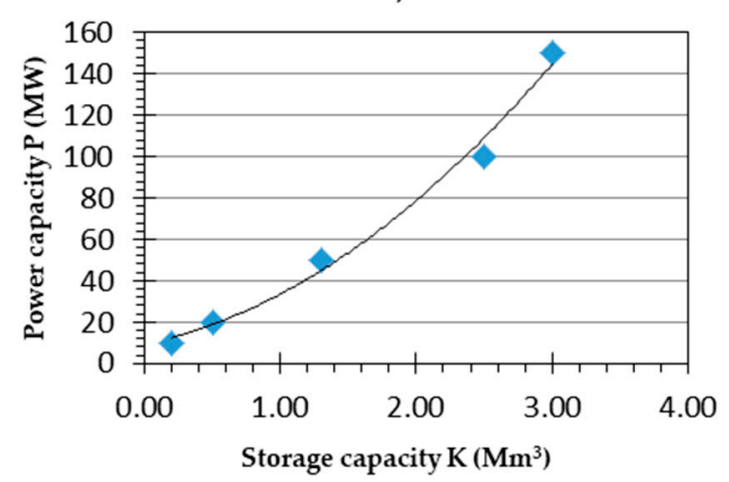

Figure 6. Cont. 
(c)

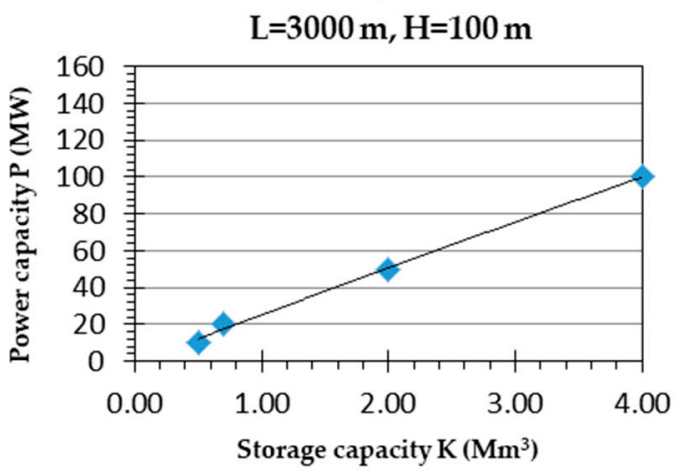

(e)

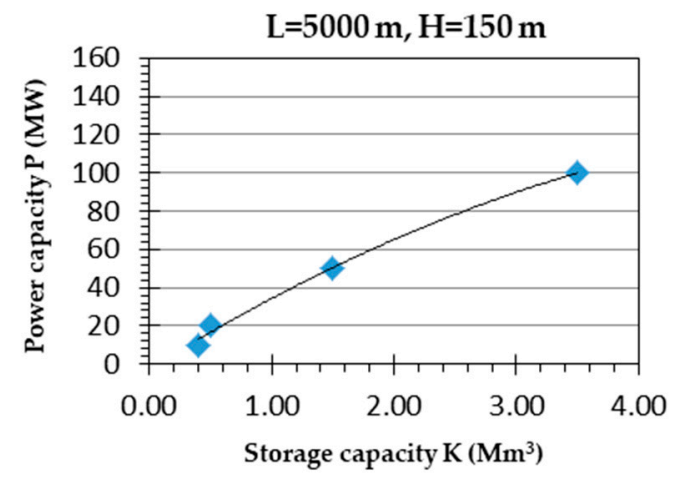

(d)

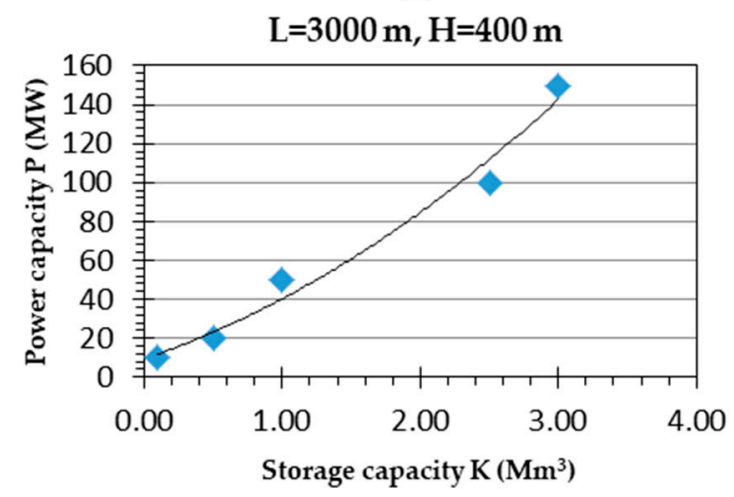

(f)

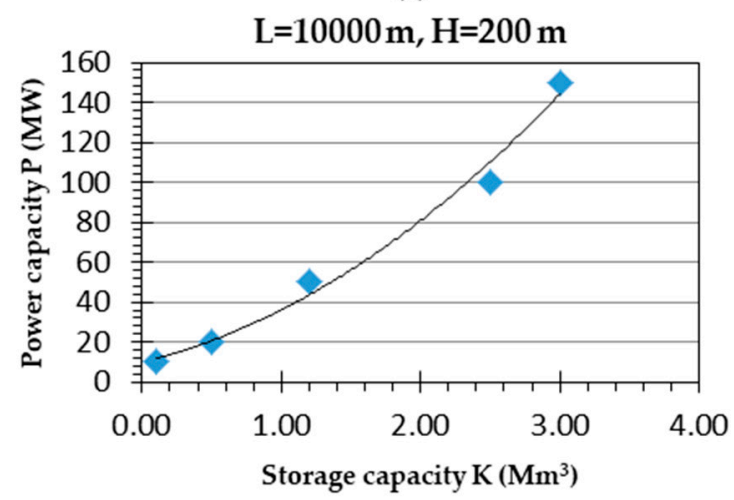

Figure 6. Plots of $(\mathrm{P}, \mathrm{K})$ pairs that maximize IRR for $(\mathbf{a}) \mathrm{L}=1000 \mathrm{~m}, \mathrm{H}=100 \mathrm{~m}$; (b) $\mathrm{L}=1000 \mathrm{~m}, \mathrm{H}=400 \mathrm{~m}$; (c) $\mathrm{L}=3000 \mathrm{~m}, \mathrm{H}=100 \mathrm{~m}$; (d) L = $3000 \mathrm{~m}, \mathrm{H}=400 \mathrm{~m}$; (e) L=5000 m, H=150 m; (f) L=10,000 m, $\mathrm{H}=200 \mathrm{~m}$.

The relationships were mildly non-linear; a similar behavior was found for all the different combinations of $\mathrm{H}$ and L. Each optimal $(\mathrm{P}, \mathrm{K})$ pair in a given $(\mathrm{L}, \mathrm{H})$ locational scenario can feature quite different NPV and IRR values from its neighbors. Such relationships may be used as a guide to determine the design characteristics of a PHS plant in the surroundings of an existing reservoir: the location of the reservoir to be built is selected according to geological and other site constraints, thereby determining $\mathrm{H}$ and $\mathrm{L}$.

In many instances, reservoir size $\mathrm{K}$ is also constrained by site characteristics, so that in this case the $\mathrm{P}-\mathrm{K}$ relationships can be used to assess $\mathrm{P}$, given $\mathrm{K}$. Once $\mathrm{P}$ and $\mathrm{K}$ are known, all the other relevant energy and economic indicators can be derived through the simulation model illustrated in Section 2.3.1.

The results presented so far, although sound from a physical point of view, must be checked for their sensitivity to the uncertainty of the relevant number of parameters that enter the calculations of the various Performance Indicators (PI) of Section 2.3.2.

The 10 parameters that are considered more uncertain, and for which the impact on the PIs needs to be investigated are listed in Table 3. Some of them are related to the 'physical' part of the model, i.e., the one dealing with energy storage and production, the others to the costs of various parts of the plants and to the benefits generated therefrom. Each of them is assumed to vary between an upper and a lower value, with a central value that was used as the base to obtain the results illustrated in the previous section.

The sensitivity of the $\mathrm{j}$-th performance index PIj to the $\mathrm{i}$-th parameter Vii is quantified by means of its elasticity Eji (e.g., [44]): 


$$
\mathrm{E}_{\mathrm{ji}}=\frac{\frac{\mathrm{PI}_{\mathrm{j}}-\mathrm{PI}_{\mathrm{j}}^{\mathrm{b}}}{\mathrm{PI}_{\mathrm{j}}^{\mathrm{b}}}}{\frac{\mathrm{VI}_{\mathrm{j}}-\mathrm{VI}_{\mathrm{i}}^{\mathrm{b}}}{\mathrm{VI}_{\mathrm{i}}^{\mathrm{b}}}}
$$

where the superscript $b$ refers to parameters and performance indexes in the base case, and the terms without superscript refer to either the upper or the lower value of the parameter and of the performance index. Performance indices for which elasticity to the parameters of Table 3 was assessed are PNV, IRR, B/C, as well as Eabs, Erel, Eff and Sat.

The latter four, deriving from the model simulating the storage-release process, are obviously insensitive to the economical parameters and in the model only depend upon pumping and generation efficiency as well as water velocity.

Table 3. Parameters considered in the sensitivity analysis and parameter range (\%s are on the central value).

\begin{tabular}{|c|c|c|c|c|c|}
\hline \multirow{2}{*}{ No } & \multirow{2}{*}{ Parameter } & & \multicolumn{3}{|c|}{ Parameter Range } \\
\hline & & & Lower Value & Central Value & Upper Value \\
\hline 1 & Reservoir cost & $\mathrm{C}_{\mathrm{K}}$ & $90 \%$ & $100 \%$ & $110 \%$ \\
\hline 2 & Generation equipment cost & $\mathrm{C}_{\text {turb }}$ & $90 \%$ & $100 \%$ & $110 \%$ \\
\hline 3 & Pumping system cost & $\mathrm{C}_{\text {pump }}$ & $90 \%$ & $100 \%$ & $110 \%$ \\
\hline 4 & Pipelines cost & $\mathrm{C}_{\text {pipes }}$ & $90 \%$ & $100 \%$ & $110 \%$ \\
\hline 5 & Total operation cost & Cgtot & $90 \%$ & $100 \%$ & $110 \%$ \\
\hline 6 & $\begin{array}{l}\text { Economic value of avoided energy } \\
\text { production from the present mix }\end{array}$ & PUN & $90 \%$ & $100 \%$ & $110 \%$ \\
\hline 7 & Value of avoided $\mathrm{CO}_{2}$ emissions & $\mathrm{CO}_{2}$ & $90 \%$ & $100 \%$ & $110 \%$ \\
\hline 8 & Efficiency of the generation system & $\eta_{t}$ & 0.80 & 0.85 & 0.90 \\
\hline 9 & Efficiency of the pumping system & $\eta_{\mathrm{p}}$ & 0.75 & 0.80 & 0.85 \\
\hline 10 & Maximum water velocity in the pipelines & $\mathrm{v}$ & $3 \mathrm{~m} / \mathrm{s}$ & $4 \mathrm{~m} / \mathrm{s}$ & $5 \mathrm{~m} / \mathrm{s}$ \\
\hline
\end{tabular}

The sensitivity analysis was performed only on plants that appear to have promising and robust performance indicators: as a selection criterion, only plants exhibiting an IRR $\geq 7 \%$ were considered. 225 plants out of the $1728(\mathrm{P}, \mathrm{K}, \mathrm{L}, \mathrm{H})$ combinations from Table 1 satisfied this criterion. In the first place, an importance analysis was carried out to understand which parameter had statistically the highest impact on the indicators. To this end, for each of the 225 plants, elasticity of the performance indicators to the 10 selected parameters of Table 3 was assessed, and they were ranked in descending order, so as to highlight to which parameter the PIs were more sensitive.

For each PI, the frequency (over the 225 plants) with which the j-th parameter ranks first, second tenth, was assessed. Results are summarized in Table 4, referring to NPV, where the values of each row and column sum to 1 . | Eji $\mid>1$ implies that a unit change in the parameter results in more than a unit change of the PI, and hence identifies the parameter as critical for the assessment of the PI [29].

Table 4 points out that, looking at NPV as performance indicator, the most impacting parameter was $\eta_{\text {turb }}$, the overall efficiency of the generation system, which ranked first as sensitive parameter in $100 \%$ of cases. After $\eta_{\text {turb }}$, the opportunity cost of energy ranked second for importance (in $96 \%$ of cases), and $\eta_{\text {pump }}$ ranked third (in $92 \%$ of cases). In concluding, the ranking of parameters according to their impact on NPV, IRR and B/C is reported in Table 5, together with the average values of elasticities. The table shows that the five most sensitive parameters were the same regardless the PI used to assess elasticity. 
Table 4. Importance matrix of the parameters analyzed. The elements of the matrix indicate the frequency (on the sample of the plants with IRR $\geq 7 \%$ ) with which a parameter ranks first to second ... tenth, by order of importance.

\begin{tabular}{ccccccccccc}
\hline \multirow{2}{*}{ Parameter } & \multicolumn{8}{c}{ Cardinality of the Order of Importance } \\
\cline { 2 - 11 } & $\mathbf{1}^{\circ}$ & $\mathbf{2}^{\circ}$ & $\mathbf{3}^{\circ}$ & $\mathbf{4}^{\circ}$ & $\mathbf{5}^{\circ}$ & $\mathbf{6}^{\circ}$ & $\mathbf{7}^{\circ}$ & $\mathbf{8}^{\circ}$ & $\mathbf{9}^{\circ}$ & $\mathbf{1 0}^{\circ}$ \\
\hline $\mathrm{C}_{\mathrm{K}}$ & 0.00 & 0.00 & 0.00 & 0.44 & 0.40 & 0.09 & 0.04 & 0.01 & 0.00 & 0.00 \\
$\mathrm{C}_{\text {pipes }}$ & 0.00 & 0.00 & 0.00 & 0.00 & 0.07 & 0.21 & 0.14 & 0.06 & 0.34 & 0.19 \\
$\mathrm{C}_{\text {turb }}$ & 0.00 & 0.00 & 0.05 & 0.50 & 0.44 & 0.01 & 0.00 & 0.00 & 0.00 & 0.00 \\
$\mathrm{C}_{\text {pump }}$ & 0.00 & 0.00 & 0.00 & 0.00 & 0.04 & 0.46 & 0.32 & 0.15 & 0.04 & 0.00 \\
$\mathrm{C}_{\text {gtot }}$ & 0.00 & 0.00 & 0.00 & 0.00 & 0.00 & 0.00 & 0.00 & 0.03 & 0.27 & 0.70 \\
$\mathrm{PUN}_{\mathrm{CO}}$ & 0.00 & 0.97 & 0.03 & 0.00 & 0.00 & 0.00 & 0.00 & 0.00 & 0.00 & 0.00 \\
$\mathrm{C}_{\mathbf{p}}$ & 0.00 & 0.00 & 0.00 & 0.00 & 0.00 & 0.04 & 0.26 & 0.52 & 0.18 & 0.00 \\
$\eta_{\mathrm{t}}$ & 0.00 & 0.03 & 0.92 & 0.04 & 0.00 & 0.00 & 0.00 & 0.00 & 0.00 & 0.00 \\
$\mathbf{v}$ & 1.00 & 0.00 & 0.00 & 0.00 & 0.00 & 0.00 & 0.00 & 0.00 & 0.00 & 0.00 \\
& 0.00 & 0.00 & 0.00 & 0.01 & 0.05 & 0.18 & 0.24 & 0.23 & 0.18 & 0.12 \\
\hline
\end{tabular}

Table 5. Parameters ordered by their impact on NPV, IRR and B/C and average elasticity values.

\begin{tabular}{|c|c|c|c|c|c|c|c|c|c|c|}
\hline Order of Importance & $1^{\circ}$ & $2^{\circ}$ & $3^{\circ}$ & $4^{\circ}$ & $5^{\circ}$ & $6^{\circ}$ & $7^{\circ}$ & $8^{\circ}$ & $9^{\circ}$ & $10^{\circ}$ \\
\hline $\begin{array}{c}\text { Parameters ordered by } \\
\text { importance-NPV }\end{array}$ & $\eta_{t}$ & PUN & $\eta_{\mathrm{p}}$ & $\mathrm{C}_{\text {turb }}$ & $\mathrm{C}_{\mathrm{k}}$ & $\mathrm{CO}_{2}$ & $C_{\text {pump }}$ & $\mathrm{C}_{\mathrm{k}}$ & $C_{\text {gtot }}$ & $\mathrm{v}$ \\
\hline $\begin{array}{l}\text { Average elasticity value } \\
\text { (over the } 225 \text { plants) - NPV }\end{array}$ & 2.56 & 2.22 & 1.79 & -0.51 & -0.52 & 0.35 & -0.25 & -0.20 & -0.15 & -0.06 \\
\hline $\begin{array}{l}\text { Parameters ordered by } \\
\text { importance-IRR }\end{array}$ & $\eta_{t}$ & PUN & $\eta_{p}$ & $\mathrm{C}_{\text {turb }}$ & $\mathrm{C}_{\mathrm{k}}$ & $C_{\text {pump }}$ & $\mathrm{CO}_{2}$ & $\mathrm{v}$ & $\mathrm{C}_{\mathrm{k}}$ & $C_{\text {gtot }}$ \\
\hline $\begin{array}{l}\text { Average elasticity value } \\
\text { (over the } 225 \text { plants) - IRR }\end{array}$ & 1.40 & 1.23 & 0.98 & -0.48 & -0.48 & 0.23 & 0.18 & 0.16 & 0.17 & -0.08 \\
\hline $\begin{array}{c}\text { Parameters ordered by } \\
\text { importance-B/C }\end{array}$ & $\eta_{t}$ & PUN & $\eta_{\mathrm{p}}$ & $\mathrm{C}_{\text {turb }}$ & $\mathrm{C}_{\mathrm{k}}$ & $\mathrm{C}_{\text {pump }}$ & $\mathrm{CO}_{2}$ & $\mathrm{~V}$ & $\mathrm{C}_{\text {gtot }}$ & $\mathrm{C}_{\mathrm{k}}$ \\
\hline $\begin{array}{l}\text { Average elasticity value } \\
\text { (over the } 225 \text { plants) }-B / C\end{array}$ & 1.00 & 0.86 & 0.70 & -0.34 & 0.33 & -0.16 & 0.14 & 0.07 & -0.09 & 0.11 \\
\hline
\end{tabular}

It is also interesting to observe how the elasticity of the PIs varied with the four parameters describing the plant: Figure $7 a-d$ shows, as an example, the pattern of $E_{N P V}, \eta_{\text {turb }}$ with $\mathrm{H}, \mathrm{L}, \mathrm{P}$ and $\mathrm{K}$. The figures reported the average value of the elasticity of the NPV to $\eta_{t u r b}$, together with an upper and lower confidence level built with the standard deviation of the elasticity. According to Figure 7, this elasticity was almost insensitive to capacity (K). Average elasticity (blue line), and consequently uncertainty, seemed to grow in the direction where conditions become less favorable for a PHS plant (small Hs and Ps, large distances Ls between reservoirs).

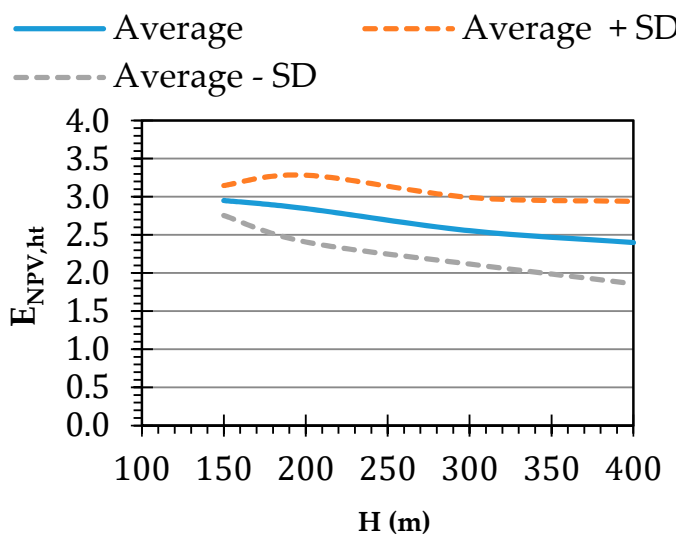

(a)

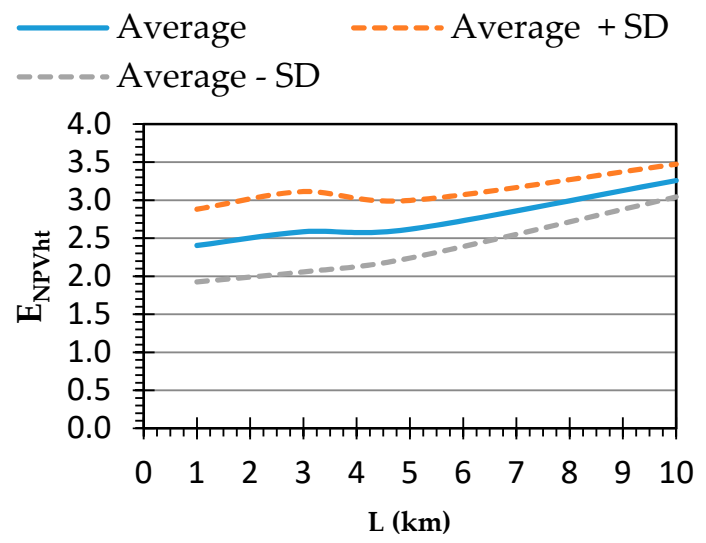

(b)

Figure 7. Cont. 


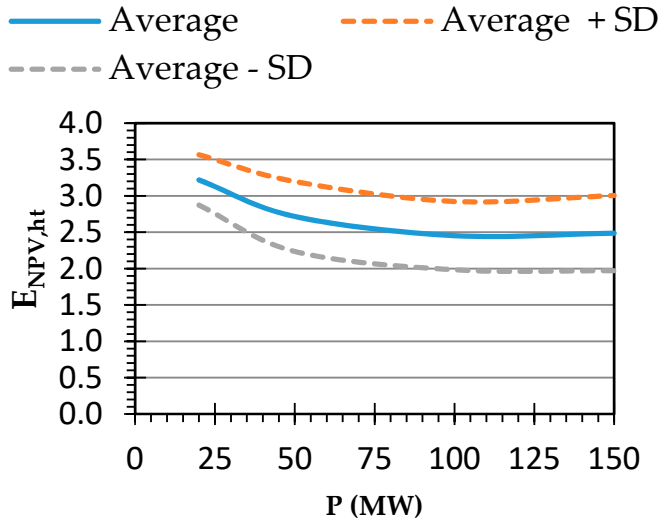

(c)
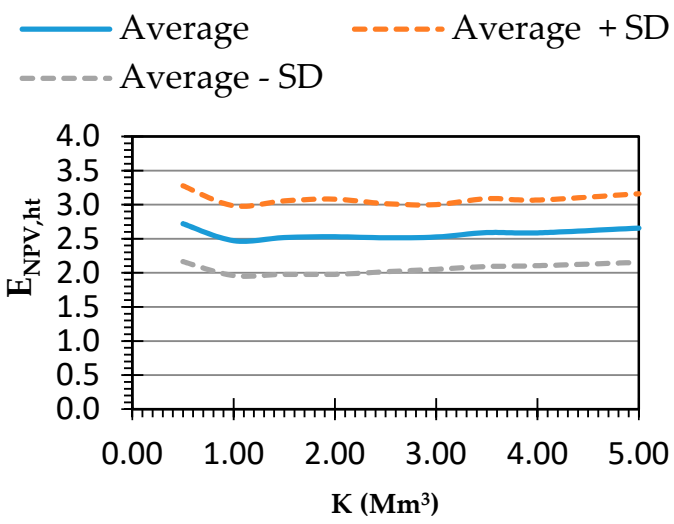

(d)

Figure 7. NPV sensitivity to $\eta_{\text {turb }}$ as a function of the head (a), distance between reservoirs (b), installed power (c), and upper reservoir's active capacity (d). Dotted lines indicate average elasticity value \pm elasticity standard deviation.

\section{Conclusions}

The paper has presented a parametric engineering-economical assessment of a PHS plant with an existing reservoir for absorbing energy surpluses from wind farms, based on production and load data from Sicily, Italy. Although conducted with site-specific data, the assessment procedure is generalizable to other areas and the results are also likely to be generalizable in contexts with duration curves of wind power surpluses similar to those of Figure 2. The assessment is aimed at understanding the economic feasibility of new facilities in a decentralized perspective, to be suitably regulated [45]. Results show that there is a wide spectrum of economically feasible plants for different plant locational and design parameters. However, constraints on minimum head between the two reservoirs are binding, in that no plant looks feasible with heads less than 70-80 m. The study has clarified the interrelation among the different key parameters of the plant, and has provided optimal relationships between storage capacity and installed power as well as insights into the sensitivity of the economic indicators to some relevant input parameters, such as the efficiency of the generation and pumping system and the unit price of energy. A number of future developments can stem from this exploratory study: in the first place, a more detailed engineering-economical analysis can be performed, based on a more realistic description of a number of processes involved in the storage and subsequent production of energy. The storage process in the existing reservoir, for example, can show head variations of up to tenths of meters during the drawdown season. As the head between the upper reservoirs and the power plant remains the same, such variations require that more energy be absorbed by the PHS to produce the same quantity of energy. The assumption of constant pumping and generation efficiency is also something of an abstraction and can be better modelled and described, especially considering that economic indicators have proven sensitive to these parameters. In addition, the potential plant could also be embedded into the whole generation system, including all the other sources with their dispatch rules and ramp-up constraints, as performed in other studies. Future research might also seek to understand the potential development of multiple plants in a target area, looking at the way they should be operated.

Finally, the method presented can be applied to a given area to complement the topographical investigations described in References [20-22], and to confirm that potentially suitable sites identified for the development of a PHS facility in the surroundings of each existing reservoir are also promising from an economic perspective.

Author Contributions: Conceptualization, C.A., M.G. and M.R.M.; Formal analysis, C.A. and A.L.; Funding acquisition, M.R.M.; Investigation, A.L. and I.M.; Methodology, C.A. and M.G.; Resources, A.L.; Software, C.A.; Supervision, C.A., M.G. and M.R.M.; Validation, M.G.; Writing—original draft, C.A.; Writing—review \& editing, M.G. and M.R.M. 
Funding: This study was commissioned by Fondazione AMGA-Genova, a no profit organization funded by Genoa's (Italy) multiutility with the aim to initiate, promote and further cultural initiatives aimed at safeguarding nature and environment, particularly in the field of water resources and water management.

Conflicts of Interest: The authors declare no conflict of interest. The funders had no role in the design of the study; in the collection, analyses, or interpretation of data; in the writing of the manuscript, or in the decision to publish the results.

\section{References}

1. Electric Power Research Institute, Inc. (EPRI). Electricity Energy Storage Technology Options—A White Paper Primer on Applications, Costs, and Benefits; Electric Power Research Institute, Inc.: Palo Alto, CA, USA, 2010.

2. Electric Power Research Institute, Inc. (EPRI). Grid Integration of Large-Capacity Renewable Energy Sources and Use of Large-Capacity Electrical Energy Storage-White Paper. 2012. Available online: www.iec.ch (accessed on 4 December 2018).

3. National Renewable Energy Laboratory. Renewable Electricity Futures Study; 4 Volumes NREL/TP-6A20-52409; Hand, M.M., Baldwin, S., DeMeo, E., Reilly, J.M., Mai, T., Arent, D., Porro, G., Meshek, M., Sandor, D., Eds.; National Renewable Energy Laboratory: Golden, CO, USA, 2012.

4. Denholm, P.; Ela, E.; Kirby, B.; Milligan, M. The Role of Energy Storage with Renewable Energy Generation; NREL Technical Report NREL/TP-6A2-47187; National Renewable Energy Laboratory: Golden, CO, USA, 2012.

5. European Commission-DG ENER. The Future Role and Challenges of Energy Storage, DG-ENER Working Paper. 2013. Available online: http://ec.europa.eu/energy/infrastructure/doc/energy-storage/2013/ energy_storage.pdf (accessed on 4 December 2018).

6. Strbac, G.; Aunedi, M.; Pudjianto, D.; Djapic, P.; Teng, F.; Sturt, A.; Jackravut, D.; Sansom, R.; Yufit, V.; Brandon, N. Strategic Assessment of the Role and Value of Energy Storage Systems in the UK Low Carbon Energy Future, Report for Carbon Trust; Energy Futures Lab, Imperial College: London, UK, 2012.

7. Eurelectric. Renewables Action Plan-Annexes. 2011. Available online: www.eurelectric.org (accessed on 4 December 2018).

8. Castronuovo, E.D.; Lopes, J.A.P. Optimal operation and hydro storage sizing of a wind-hydro power plant. Electr. Power Energy Syst. 2004, 26, 771-778. [CrossRef]

9. Connolly, D.; Lund, H.; Finn, P.; Mathiesen, B.V.; Leahy, M. Practical operation strategies for pumped hydroelectric energy storage (PHES) utilising electricity price arbitrage. Energy Policy 2011, 39, 4189-4196. [CrossRef]

10. Parastegari, M.; Hooshmand, R.-A.; Khodabakhshian, A.; Forghani, Z. Joint operation of wind farms and pump-storage units in the electricity markets: Modeling, simulation and evaluation. Simul. Model. Pract. Theory 2013, 37, 56-69. [CrossRef]

11. Muche, T. Optimal operation and forecasting policy for pump storage plants in day-ahead markets. Appl. Energy 2014, 113, 1089-1099. [CrossRef]

12. Korpaas, M.; Holen, T.; Hildrum, R. Operation and sizing of energy storage for wind power plants in a market system. Int. J. Electr. Power Energy Syst. 2003, 25, 599-606. [CrossRef]

13. Yang, C.-J.; Jackson, R.B. Opportunities and barriers to pumped-hydro energy storage in the United States. Renew. Sustain. Energy Rev. 2011, 15, 839-844. [CrossRef]

14. Ardizzon, G.; Cavazzini, G.; Pavesi, G. A new generation of small hydro and pumped-hydro power plants: Advances and future challenges. Renew. Sustain. Energy Rev. 2014, 31, 746-761. [CrossRef]

15. Kapsali, M.; Anagnostopoulos, J.S.; Kaldellis, J.K. Wind powered pumped-hydro storage systems for remote islands: A complete sensitivity analysis based on economic perspectives. Appl. Energy 2012, 99, 430-444. [CrossRef]

16. Papaefthymiou, S.V.; Papathanassiou, S.A. Optimum sizing of wind-pumped-storage hybrid power stations in island systems. Renew. Energy 2014, 64, 187-196. [CrossRef]

17. Kaldellis, J.K.; Zafirakis, D.; Kavadias, K. Techno-economic comparison of energy storage systems for island autonomous electrical networks. Renew. Sustain. Energy Rev. 2009, 13, 378-392. [CrossRef]

18. Kane, M. Development of Bulk Energy Storage \& Natura 2000, Deliverable 3.3. STOre Project. 2012. Available online: www.store-project.eu (accessed on 4 December 2018). 
19. Genco, M. Ricerca su l'uso delle capacità residue di laghi artificiali esistenti come accumulo di energia elettrica Attività propedeutica Fasi 1 e 2-Rapporto Finale, 2015. Available online: http:/ / www.fondazionamga.it (accessed on 4 December 2018).

20. Arántegui, R.L.; Fitzgerald, N.; Leahy, P. Pumped-Hydro Energy Storage: Potential for Transformation from Single Dams, JRC-IET Report EUR 25239 EN; European Union: Luxembourg, 2011.

21. Connolly, D.; MacLaughin, S.; Leahy, M. Development of a computer program to locate potential sites for pumped hydroelectric energy storage. Energy 2010, 35, 375-381. [CrossRef]

22. Gimeno-Gutiérrez, M.; Lacal-Arántegui, R. Assessment of the European Potential for Pumped Hydropower Energy Storage; JRC Scientific and Policy reports; European Union: Luxembourg, 2013; ISBN 978-92-79-29511-9.

23. Bueno, C.; Carta, C. Wind powered pumped hydro storage systems, a means of increasing the penetration of renewable energy in the Canary Islands. Renew. Sustain. Energy Rev. 2006, 10, 312-340. [CrossRef]

24. Anagnostopoulos, J.; Papantonis, D. Simulation and size optimization of a pumped-storage power plant for the recovery of wind-farms rejected energy. Renew. Energy 2008, 33, 1685-1694. [CrossRef]

25. Rozali, N.E.M.; Alwi, S.R.W.; Mananam, Z.A.; Klemeš, J.J.; Mohammad Yusri Hassan, M.Y. Optimisation of Pumped-Hydro Storage System for Hybrid Power System Using Power Pinch Analysis. Chem. Eng. Trans. 2013, 35, 85-90. [CrossRef]

26. Benitez, L.E.; Benitez, P.C.; Van Kooten, G.C. The economics of wind power with energy storage. Energy Econ. 2008, 30, 1973-1989. [CrossRef]

27. Parfomak, P.W. Energy Storage for Power Grids and Electric Transportation: A Technology Assessment; CRS Report for Congress; Congressional Research Service: Washington, DC, USA, 2012. Available online: https: / / fas.org/sgp/crs/misc/R42455.pdf (accessed on 4 December 2018).

28. Servizio Informativo Agrometeorologico Siciliano. Available online: http://www.sias.regione.sicilia.it (accessed on 4 December 2018).

29. Jacobson, N. Basic Algebra 1, 2nd ed.; Dover Publications: Mineola, NY, USA, 2009; ISBN 978-0-486-47189-1.

30. EC-Directorate General Regional Policy. Guide to Cost-Benefit Analysis of Investment Projects; Publications Office of the European Union, European Union: Luxembourg, 2015; ISBN 978-92-79-34796-2.

31. Florio, M. Applied Welfare Economics-Cost-Benefit Analysis of Projects and Policies; Routledge: London, UK, 2014; ISBN 978-0-415-85833-5.

32. Regione Siciliana, Nuovo Prezziario Unico Regionale per i Lavori Pubblici 2013. Available online: https: / / www.acca.it/prezzario-regione-sicilia (accessed on 27 November 2018).

33. Alvarado-Anceida, C.A. Estimating E\&M Powerhouse Costs, International Water Power\& Dam Construction. 2009. Available online: http:/ / www.waterpowermagazine.com/ (accessed on 4 December 2018).

34. Black, M.; Strbac, G. Value of storage in providing balancing services for electricity generation systems with high wind penetration. J. Power Sources 2006, 162, 949-953. [CrossRef]

35. Denholm, P.; Ela, L.; Kirby, B.; Milligan, M. The Role of Energy Storage with Renewable Electricity Generation; NREL/TP-6A2-47187; National Renewable Energy Laboratory: Golden, CO, USA, 2010.

36. Rahimi, E.; Rabiee, A.; Aghaei, J.; Muttaqi, K.M.; Nehzad, A.E. On the management of wind power intermittency. Renew. Sustain. Energy Rev. 2013, 26, 643-653. [CrossRef]

37. Chang, M.K.; Eichman, D.J.; Mueller, F.; Samuelsen, S. Buffering intermittent renewable power with hydroelectric generation: A case study in California. Appl. Energy 2013, 112, 1-11. [CrossRef]

38. Nyamdash, B.; Denny, E. The impact of electricity storage on wholesale electricity prices. Energy Policy 2013, 58, 6-16. [CrossRef]

39. Gast, N.; Le Boudec, J.; Proutiere, A.; Tomozei, D. Impact of storage on the efficiency and prices in real-time electricity markets. In Proceedings of the e-Energy '13, Berkley, CA, USA, 21-24 May 2013.

40. Connolly, D.; Lund, H.; Mathiesen, B.V.; Pican, E.; Leahy, M. The technical and economic implications of integrating fluctuating renewable energy using energy storage. Renew. Energy 2012, 43, 47-60. [CrossRef]

41. Vennemann, P.; Gruber, K.H.; Haaheim, J.U.; Kunsch, A.; Sistenich, H.-P.; Thöni, H.-R. Pumped storage plants-Status and perspectives. VGB PowerTech 2011, 4/2011, 32-38.

42. Donalek, P.; Clark, H.; Nakata, R.; Stein, J. Application of Adjustable Speed Doubly Fed Machines in Pumped Storage and Conventional Hydroelectric Plants. In Proceedings of the American Power Conference, Chicago, IL, USA, 13-15 April 1993; Volume 55-I, pp. 245-290.

43. Donalek, P.; Clark, H. Application of Adjustable Speed Machines in Conventional and Pumped Storage Hydro Projects; EPRI: Palo Alto, CA, USA, 1995. 
44. Loucks, D.P.; Van Beek, E. Water Resources Systems Planning and Management-An Introduction to Methods, Models and Applications; UNESCO Publishing: Paris, France, 2005; ISBN 92-3-103998-9.

45. Schill, W.P.; Kemfert, C. Modeling Strategic Electricity Storage: The Case of Pumped Hydro Storage in Germany. Energy J. 2013, 32, 59-87. [CrossRef]

(c) 2018 by the authors. Licensee MDPI, Basel, Switzerland. This article is an open access article distributed under the terms and conditions of the Creative Commons Attribution (CC BY) license (http://creativecommons.org/licenses/by/4.0/). 